\title{
Single Genetic Stock Revealed by Microsatellite Markers Among Wild Populations of Cirrhinus mrigala from Peninsular India
}

\author{
Sofia P. Das ${ }^{1,2}$, Subrat K. Swain ${ }^{1,4}$, Lakshman Sahoo ${ }^{1}$, Joy Krushna Jena ${ }^{3}$, \\ Paramananda Das ${ }^{1, *}$
}

${ }^{1}$ ICAR-Central Institute of Freshwater Aquaculture, Fish Genetics and Biotechnology Division, Kausalyaganga, Bhubaneswar, Odisha, India.

${ }^{2}$ Amity University Uttar Pradesh, Amity Institute of Marine Science and Technology, Sector-125, Noida, India.

${ }^{3}$ Division of Fisheries, Krishi Anusandhan Bhawan - II, New Delhi, India.

${ }^{4}$ SOA University, IMS and SUM Hospital, Center for Genomics and Biomedical Informatics, K8, Kalinga Nagar, Bhubaneswar, India

\section{How to cite}

Das, S.P., Swain, S.K., Sahoo, L., Jena, J.K., Das, P. (2021). Single Genetic Stock Revealed by Microsatellite Markers Among Wild Populations of Cirrhinus mrigala from Peninsular India. Turkish Journal of Fisheries and Aquatic Sciences, 21, 425-433. http://doi.org/10.4194/1303-2712-v21_9_01

\section{Article History}

Received 15 November 2020

Accepted 24 May 2021

First Online 26 May 2021

\section{Corresponding Author}

Tel.: +919437291615

E-mail: pdas77@hotmail.com

\section{Keywords}

Cirrhinus mrigala

Population structure

Microsatellite

Genetic stock

\begin{abstract}
Cirrhinus mrigala (mrigal) is one of the Indian major carps widely cultured in the whole Indian subcontinent. Population genetic structure of this species from Peninsular Rivers of India is lacking. Among DNA markers, microsatellites are excellent tools to evaluate genetic variation of populations. In this study, genetic variation of six peninsular riverine mrigal populations was evaluated using seventeen microsatellite loci. In analyzing 288 samples, the number of alleles ranged from 4 to 27; observed heterozygosity from 0.595 to 1.00 , expected heterozygosity from 0.586 to 0.959 and inbreeding coefficient $\left(F_{I S}\right)$ ranged from -0.034 to 0.02 . Exact test for Hardy Weinberg disequilibrium revealed that one locus was not in equilibrium across the rivers except one. The AMOVA analysis revealed the main source of genetic variation to be within the population $(94.54 \%)$ than among the populations $(5.46 \%)$. The Nei's genetic distance and structure analysis depict river Narmada and Mahi populations are different from the four east coast rivers. The overall Fst $(0.05462)$ data showed moderate differentiation among the six populations. The results of this study provide essential information to resource recovery and help in delineating populations for fishery management. Besides, the data will provide a valuable baseline for further investigations on the geographic distribution of this commercially important fish species.
\end{abstract}

\section{Introduction}

The Indian carps are the most widely cultivated species throughout the peninsular region. Mrigal (Cirrhinus mrigala), a carp endemic to Indo-Gangetic riverine systems, is one of the three Indian major carp species cultivated widely in Southeast Asian countries. The species was transplanted in the peninsular riverine systems of India, where it has established itself. Subsequently, it has spread over whole of India. According to FAO (2005-2020) contribution of aquaculture sector is one third of the Indian's total fish production i.e, 9.06 million tonnes during 2012-2013. The total aquaculture production was valued at US\$ 3.5 billion of which carp alone was responsible for as much as 4.18 million tonnes. Whereas, aquaculture production of only mrigal carp in 2009 was 497,493 tonnes that translates to approximately $0.9 \%$ of global aquaculture production, stated by FAO (2012). Wild capture fishery of mrigal is, however, exhibiting a declining trend. Comparison of capture survey data from 1958-1994 indicates an 87\% decline in mrigal fishery in the Indian rivers (Payne et al., 2004). In global context India and Bangladesh both belongs to the major producer category of mrigal.

The lack of knowledge about the genetic structure of mrigal populations may result in the differential harvest of the populations that will ultimately have a 
drastic and long-term effect. To overcome this, there is always a need for investigations encompassing the genetic variations at the intra and inter-population levels as well as at the intra and inter-specific levels of the fish and shellfish resources of any nation (Allendorf and Utter, 1979). With the depletion of mrigal fishery and rapid increase in hatchery production, it is necessary to understand the genetic composition to evaluate the genetic structure and intermixing of gene pool.

A microsatellite, also known as simple sequence repeat (SSR), consists of multiple copies of tandemly arranged repeats ranging in size from one to six base pairs. Microsatellites are the most versatile ones among molecular markers and are co-dominant in nature (Tautz, 1989). Although identifying microsatellite in a species of interest can be time consuming but the techniques employed are well established and reliable. Microsatellite markers have proven to be an exceptional indicator of genetic variation within and between populations of many fishery animals, including invertebrates (Aranishi and Okimoto, 2005; An et al., 2013a; Kim et al., 2013). The principal drawbacks of this marker are requirement of species specific primers, a relatively large number of microsatellites might be necessary to achieve sufficient statistical power, which can be labor intensive and expensive (Olafsson et al., 2010) and to overcome this problem cross species amplification technique is being used for achieving cost effectiveness. The success rate of cross-species microsatellite amplification is directly related to evolutionary and relatedness of loci isolated and the species to which the heterologous loci are being applied (Primmer CR et al., 1996). A few pairs of highly polymorphic microsatellites can be enough if the objective is to address genetic diversity related questions. Only few studies have characterized the population genetic structure of mrigal fishery; one is through microsatellite and allozyme (Chauhan et al., 2007) but from Himalayan region and others are mitochondrial Cyt $b$ gene, ATPase- 6 gene and truss morphometrics (Das et al., 2014. 2018 and Behera et al., 2015). The microsatellite markers exhibited a common gene pool in mrigal population from Himalayan region where as mitochondrial marker analysis showed a low level of genetic variation with a single genetic stock throughout the peninsular region. Therefore, to protect the mrigal population and to promote its sustainable exploitation, the present status of its genetic diversity and the relatedness of populations throughout its geographic range must be determined using molecular genetic analysis.

In the present study, we investigated the genetic diversity within and between six mrigal populations along with the genetic structure of this species in peninsular India using 17 microsatellite loci. This genetic information will be useful for resource management and conservation of this economically important fish species.

\section{Material and Methods}

\section{Sample Collection and DNA Extraction}

This study examined 288 wild Cirrhinus mrigala from peninsular riverine systems of India. We have collected samples from six riverine sources i.e. Mahanadi (Cuttack), Godavari (Rajahmundry), Krishna (Vijaywada), Kaveri (Bangalore), Narmada (Varuch) and Mahi (Aanand) (Table-1). The live fish samples were caught by gill net or cast net and morphological identification of species was done based on Talwar and Jhingran (1991). Fin clipping was done from each individual fish, preserved in $95 \%$ ethanol and stored frozen at $-20^{\circ} \mathrm{C}$ until DNA extraction. Total DNA was isolated from fin tissues by Proteinase $\mathrm{K}$ digestion followed by standard Phenol-Chloroform method by Sambrook and Russel, 2001. The DNA samples were subsequently dissolved in $1 X$ TE buffer. The purity and concentration of the DNA samples were estimated in $260 / 280$ nm wavelength by a Spectrophotometer.

\section{Isolation of Microsatellite Markers}

A set of polymorphic microsatellite markers for this species was developed by cross amplifying highly informative rohu repeat sequences already developed in our laboratory earlier (Das et al., 2005; Patel et al., 2009; Sahu et al., 2012). Out of 150 rohu microsatellite loci, seventeen microsatellite loci were chosen based on specific amplification in mrigal from screening of more than 37 rohu loci. This primer panel of 17 was fluorescence labeled (either FAM or HEX) and used for population genetic studies (Table - 2).

\section{Cross-species Amplification}

One hundred and fifty rohu microsatellite loci developed earlier as mentioned above were selected for cross amplification and polymorphism screening in a set

Table 1. Geographical co-ordinate of locations along with sample sizes and year of sampling.

\begin{tabular}{lccc}
\hline Rivers & Sampling sites & $\mathrm{n}$ & Year of sampling \\
\hline Mahanadi & Cuttack (20.27ㅇN85.52으) & 48 & 2009 \\
Godavari & Rajahmundry (16.59N81.47으) & 48 & 2010 \\
Krishna & Vijayawada (16.31ㅇN80.37으) & 48 & 2011 \\
Kaveri & Mysore (12.18ㅇN76.38으) & 48 & 2011 \\
Narmada & Varuch (21.7N72.97으) & 48 & 2012 \\
Mahi & Anand (22.57ㅇN72.93으) & 48 & 2012 \\
\hline
\end{tabular}


Table 2. List of microsatellite loci amplified in wild population of C. mrigala.

\begin{tabular}{|c|c|c|c|c|c|}
\hline Locus name & Forward and Reverse Sequence $\left(5^{\prime}-3^{\prime}\right)$ & Poduct size & Accession no. & Primer Label & Motif \\
\hline \multirow[t]{2}{*}{ Lr-206 } & F- GAAGTGTTTGTGTGGCTGGA & 182 & JN581273 & Fam & (TG)25 \\
\hline & R- CCGGTGGGATCTGTGTATG & & & & \\
\hline \multirow[t]{2}{*}{ Lr-298 } & F- TGGTCCCATAACGTGATGAAT & 246 & JN581361 & Fam & (AC)17 \\
\hline & R- GAAAACAGGCATCTGAACACAA & & & & \\
\hline \multirow[t]{2}{*}{ Lr-36 } & F- AGC GTG TCT GAT GTG TGA AAG G & 181 & AM269526 & Hex & $(\mathrm{CA})_{10}$ \\
\hline & R- TCA GAT GCC TCC TGC ATT CTG & & & & \\
\hline \multirow[t]{2}{*}{ Lr-162 } & F- GCGAAACAGCAGCAACACT & 209 & JN581239 & Fam & $(\mathrm{AC}) 34$ \\
\hline & R- AAGAGAAGGCTTCACCTGGA & & & & \\
\hline \multirow[t]{2}{*}{ Lr-485 } & F- TCTACAGCACACTGACCCTG & 170 & JQ862222 & Fam & (TC)12 \\
\hline & R- AGTAACCGACAATCTGTGGC & & & & \\
\hline \multirow[t]{2}{*}{ Lr-231a } & F- CTATCGTTTGCTTGTTCGTTTG & 202 & JN581295 & Hex & (АTCT)6 \\
\hline & R- GATGGACGAATCGACAGATAGA & & & & \\
\hline \multirow[t]{2}{*}{ Lr-237 } & F- CAGCAGGACTGAAGAAATGTATG & 199 & JN581335 & Fam & (CA)10 \\
\hline & R- TGTAGGGCGATAGAAAGTACGG & & & & \\
\hline \multirow[t]{2}{*}{ Lr-545 } & F- ACTCCTCCTGACACCTTGAG & 236 & JQ862282 & Hex & $(\mathrm{TGA}) 9$ \\
\hline & R- ACGAACAGTGCAAAGACGTG & & & & \\
\hline \multirow[t]{2}{*}{ Lr-251a } & F- GAGGTCAGTTGGTCAGAGTTCA & 193 & JN581315 & Fam & (CA) 15 \\
\hline & R- ACCCTTTCACACCCCTCTTATT & & & & \\
\hline \multirow[t]{2}{*}{ Lr-547 } & F- CTGTAGATGCTGGTCTGGGG & 238 & JQ862284 & Hex & (CAT)10 \\
\hline & R- ACCTTACATTGGCTGTTGGTC & & & & \\
\hline \multirow[t]{2}{*}{ Lr-432 } & F- GGTTGGGATAGGGGACAGAC & 138 & JQ862170 & Hex & (GT)13 \\
\hline & R- GCTCCCCAGAATGCCTAAAC & & & & \\
\hline \multirow[t]{2}{*}{ Lr-158 } & F- CAGCAAACACACTCCTGTCAAA & 274 & JN581271 & Fam & (AC) 15 \\
\hline & R- GACGCGCAAATCAAAGTGAG & & & & \\
\hline \multirow[t]{2}{*}{ Lro-32 } & F- ACC CTC TTT GTT TTG GCT CTC & 136 & AM184148 & Hex & (GT)17 \\
\hline & R- TCT CTT ACC CTG TTT CTC TGT & & & & \\
\hline \multirow[t]{2}{*}{ Lr-51a } & F- CCCATAACGTGATGAATACC & 172 & JN581361 & Fam & (CA)9 \\
\hline & R- AGGCATCTGAACACAAGAACAC & & & & \\
\hline \multirow[t]{2}{*}{ Lr-189 } & F- GATCAGAGCAATATTGGGGTTT & 219 & JN581257 & Fam & (CA)13 \\
\hline & R- AGAAGCTGCTGTGTGCAGAA & & & & \\
\hline \multirow[t]{2}{*}{ Lro-41 } & F- GACTTCAGCTTCTCCACTCAA & 144 & AM184156 & Hex & (CTT)2 (GT)8 \\
\hline & R- CTGCGTTTAACCAATCACAA & & & & (CT)7 \\
\hline \multirow[t]{2}{*}{ Lr-63 } & F- CTTGGAATCCCCTCAATTAGC & 154 & JN581148 & Fam & (TC) 9 \\
\hline & R- ACTGATAGGGAGACAGAAAG & & & & \\
\hline
\end{tabular}

of 3-5 individuals initially from six different populations. PCR was performed in a $10 \mu$ reaction volume containing 5 ng genomic DNA, 2.5 pmol of each forward and reverse primers, $200 \mu \mathrm{M}$ of each $d \mathrm{NTP}, 1.5 \mathrm{mM}$ $\mathrm{MgCl}_{2}$ and 0.25 units Taq DNA polymerase (Bangalore Genei). Amplification was carried out with the touchdown PCR profile on a GeneAmp 9700 thermal cycler (Applied Biosystem, USA) with the following temperature setting for all primers: Initial denaturation of $94^{\circ} \mathrm{C}$ for $5 \mathrm{~min}$ ( $1 \mathrm{cycle}$ ) followed by $45 \mathrm{~s}$ at $94^{\circ} \mathrm{C}$ (denaturation), $45 \mathrm{~s}$ annealing at required temperature and $1 \mathrm{~min}$ extension at $72^{\circ} \mathrm{C}$ for each cycle. Annealing temperature started from $60^{\circ} \mathrm{C}$ to $55^{\circ} \mathrm{C}$ in successive $1^{\circ} \mathrm{C}$ difference in each step. Two cycles of amplification were set for each annealing temperature but 25 rounds of amplification were performed at final annealing temperature making the total number of cycles 35 . The PCR products were then checked for amplification and informativeness in 3\% agarose gel electrophoresis.

\section{Multiplex PCR Optimization and Genotyping}

PCR reactions for 17 fluorescence labeled primers were carried out in $10 \mu \mathrm{l}$ reaction volumes containing $1 \mathrm{x}$ Taq DNA polymerase reaction buffer, 5 pmol of each primer, $200 \mu \mathrm{M}$ dNTPs, 0.25 units of Taq DNA polymerase and $20 \mathrm{ng}$ genomic DNA as template. All 17 loci were grouped into 6 multiplex panels considering their product size (Table - 2). Amplification was performed in a GeneAmp 9700 Thermocycler (Applied Biosystems, USA) programmed for initial denaturation of $4 \mathrm{~min}$ at $94^{\circ} \mathrm{C}$ followed by 30 cycles of $45 \mathrm{~s}$ at $94^{\circ} \mathrm{C}, 1$ min at annealing temperature of corresponding primer and $2 \mathrm{~min}$ at $72^{\circ} \mathrm{C}$, and finally a $7 \mathrm{~min}$ extension at $72^{\circ} \mathrm{C}$. PCR amplification was carried out following Das et al., (2005). PCR products were 150 times diluted before taking $1 \mu \mathrm{l}$ each to be mixed with $11 \mu \mathrm{l}$ of $\mathrm{Hi}-\mathrm{Di}$ formamide and $0.1 \mu \mathrm{l}$ of GeneScan ${ }^{\mathrm{TM}}-500 \mathrm{LIZ}^{\mathrm{TM}}$ as internal size standard (Applied Biosystems, USA). The mixtures were denatured at 950 $C$ for 5 min and loaded in 310 Genetic Analyzer (Applied Biosystems, USA).

\section{Data Analysis}

All the samples from six wild populations of $C$. mrigala were genotyped using the microsatellite marker panels. Fragment size was measured according to the GeneScan ${ }^{\mathrm{TM}}-500$ LIZ $^{\mathrm{TM}}$ size standards (ABI) using GeneMapper v.3.7 software (Applied Biosystems, USA). General diversity measures of mrigal population such as 
number of alleles, observed heterozygosity (HO), expected heterozygosity $(\mathrm{HE})$ and probability test for Hardy-Weinberg Equilibrium (HWE) were studied using GDA software (Lewis and Zaykin 2000). Pairwise linkage disequilibrium (LD) among loci was tested using allele frequency for loci that were in HWE and genotypic frequencies were used to calculate LD of loci that deviated from HWE to prevent interference from withinlocus disequilibrium. For null alleles and scoring errors MICRO-CHECKER program (van Oosterhout et al., 2004) was used to check microsatellite data. Analysis of molecular variance to measure genetic variation within and among populations, genetic differentiation and pairwise Fst values were calculated using ARLEQUIN version 3.11 (Excoffier et al., 2005). STRUCTURE version 2.3 (Pritchard et al., 2000; Falush et al., 2003, 2007) was used to predict the number of clusters (K) by using Markov chain Monte Carlo methods (MCMC) to estimate allele frequencies and the probability of individual assignment to each cluster. The parameter sets assumed were admixture allele models with correlated allele frequencies and with no prior population location information. The number of clusters was set from $K=1$ to 10 with four simulations for each K. Each run consisted of a burn-in period of 50,000 steps followed by 100,000 MCMC replicates.

\section{Results}

\section{Marker Development}

Development of repeat markers, particularly microsatellites, from a species of interest is a tedious process of constructing partial genomic library involving restriction enzyme digestion, cloning, colony hybridization, sequencing of positive clones and finally primer designing from flanking regions. Though the Next Generation and high throughput sequencing technologies are available now to sequence a portion of a genome and search for microsatellite markers, in either case it is costly and time consuming. However, a primer designed from one species may work well in closely related species through cross species amplification. Successful cross amplification of microsatellite loci has been reported in catla (Mohindra et al., 2001), rohu (Das et al., 2005), Indian snow trout (Barat et al., 2011), mahseer species (Esa et al., 2008). In the present study, rohu microsatellite loci have been used in mrigal. Rohu, catla and mrigal being closely related to each other offer the possibility to take advantage of cross species amplification. Cross species amplification of 150 polymorphic rohu loci in mrigal resulted in good amplification at 37 loci. Polymorphism check of these on $3 \%$ agarose gel resulted in seventeen loci that were polymorphic in mrigal. The results indicated that about $25 \%$ of the rohu microsatellite markers can be cross amplified which can be utilized for different studies in mrigal.

\section{Genetic Variation}

High throughput multiplex genotyping of these loci showed polymorphism in all the 6 populations. All the mrigal populations were genetically diverse, with high allelic richness. Number of alleles per locus ranged from 4 to 27 , observed heterozygosity from 0.595 to 1.00 , expected heterozygosity from 0.586 to 0.959 and inbreeding coefficient $\left(F_{I S}\right.$ ) ranged from -0.034 to 0.02 . The average number of alleles, observed heterozygosity ( $\mathrm{Ho})$, expected heterozygosity $(\mathrm{He})$ and $\mathrm{p}$ value for $\mathrm{HWE}$ per locus per population are presented in Table-3. Observed heterozygosity values were found to be relatively higher and within the range (0.05-0.07).

Exact tests (3,200 iterations) for Hardy Weinberg equilibrium (HWE) showed Lr-36 in all population except Mahanadi and Lr-231a in all population except in Kaveri followed by Lro-32 in Mahanadi, Godavari and Kaveri, Lr-251a in Mahanadi, Godavari and Krishna, Lr-545 in Mahanadi, Godavari and Kaveri, Lr-485 in Godavari and Narmada, Lr-237 in Mahanadi and Godavari, Lro-41 in Godavari and Kaveri, Lr-206 in Kaveri, Lr-432, Lr-63 and Lr-51a in Godavari and Lr-162, Lr-547 and Lr-158 in Mahanadi population to be significantly deviating from HWE at 5\% significance level (Table - 3).

\section{Population Genetic Differentiation}

AMOVA analysis showed that out of total variation, only $5.46 \%$ was due to among population and $94.54 \%$ was due to within population differences (Table - 4). The pairwise Fst values ranged from -0.00284 (Krishna and Kaveri) to 0.14863 (Kaveri and Mahi) (Table - 5). All the pair-wise comparisons except Krishna-Kaveri and Narmada-Mahi showed significant genetic differentiation among population. The UPGMA dendrogram based on Nei's (1972) genetic distance showed three clusters (Fig. 1). The Mahanadi and Godavari populations were in one cluster, Krishna and Kaveri were in one and Narmada and Mahi populations were in the other cluster. The clustering result is pertinent to their geographic distribution. To investigate the population structure at the regional level, we applied a Bayesian model-based clustering algorithm implemented in the STRUCTURE program, which estimates the shared population ancestry of individuals purely on the basis of genetic data without considering population location information. The whole dataset provided a best fit model of cluster determination detected three clusters at $\Delta K=5$, suggesting that the 288 individuals partitioned into three clusters (Fig. 2). STRUCTURE analysis separated samples with respect to their geographical distribution and the result is similar to the dendrogram obtained from the genetic distance.

\section{Discussions}

Genetic diversity is the key feature for any trait improvement whereas; genetic structure analysis is a 


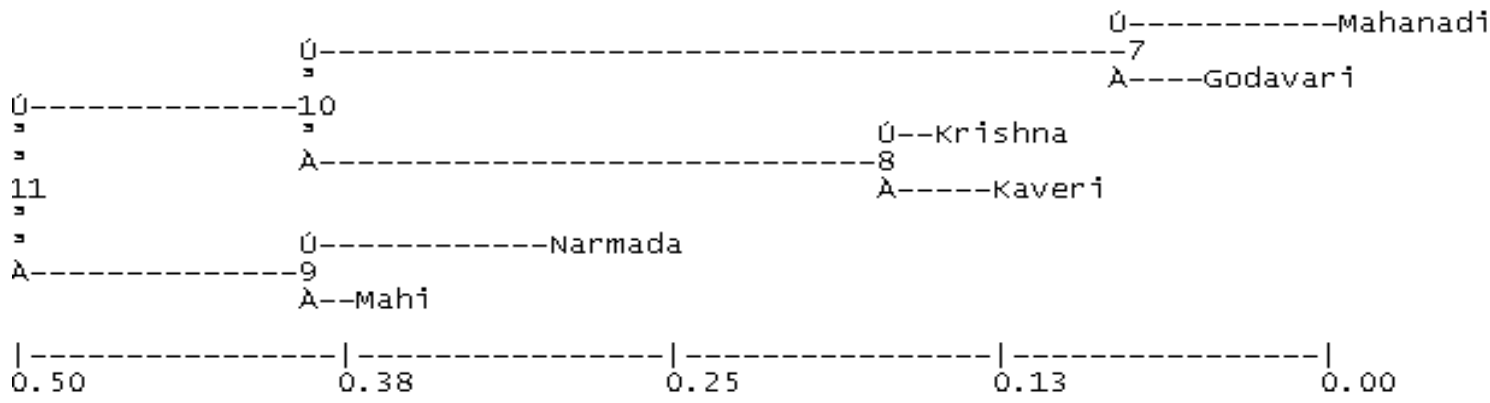

Figure 1. Dendrogram based Nei's genetic distance summarizing variations among 6 populations of $C$. mrigala using microsatellite markers.

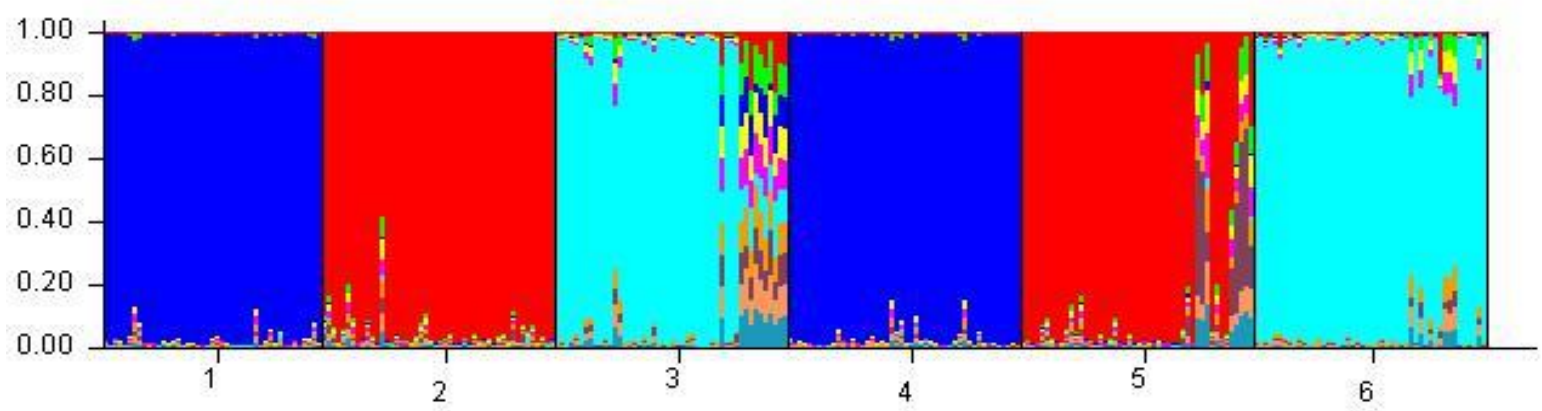

Figure 2. Genetic Structure visualization for the Bayesian population assignment test for 6 populations of $C$. mrigala using 17 microsatellite markers.

Created with STRUCTURE for $\mathrm{K}=5$; each population represented as a single, vertical bar ( $1=$ Mahanadi population, $2=$ Krishna population, $3=$ Narmada, 4= Godavari, 5= Kaveri \& 6= Mahi Populations), is partitioned into K colored segments. 288 individuals clustered into three different genetic groups. The proportions of the colour bars represent the admixtures in the varieties. The $Y$-axis shows the estimated ancestry of each genotype from a particular group

raw material for genetic variability, population differentiation with respect to evolution and geographical range of stocks. In the present investigation, genetic diversity study as well as population structure of six wild riverine stocks of mrigal were studied.

Number of alleles per locus ranged from 4 to 27, observed heterozygosity from 0.595 to 1.00 , expected heterozygosity from 0.586 to 0.959 and inbreeding coefficient $\left(F_{I S}\right)$ ranged from -0.034 to 0.02 . For each population, expected heterozygosity $(\mathrm{He})$ was generally lower than the observed heterozygosity ( $\mathrm{Ho}$ ) leading to negative inbreeding coefficients (Fis). Several factors such as wide geographical distribution, migration and mutation etc. are responsible for maintaining genetic variability within a species. Observed heterozygosity values were also relatively high and within the range (0.05-0.07) reported for teleost fish species described by Nevo (1978). As reported for several vertebrates (Nevo et al., 1984) and plants (Frankham, 1996), populations of widespread species often show significantly higher heterozygosity estimates than for populations of species with more restricted distribution.

No significant $(P>0.05)$ linkage disequilibrium was detected between different genotypes at each of the different microsatellite loci. Particularly with microsatellites, one possible explanation for these observations may be the presence of null alleles that do not amplify allowing heterozygotes difficult to distinguish (Van Oosterhout et al., 2004). But, the analysis of data using Micro-Checker did not give any evidence for null allele homozygotes in mrigal populations.

It is elsewhere suggested that if the Fst value between a pair is less than 0.05 , the populations are expected to be one. Considering the range of significant Fst values in the present study, it is apparent that 4 populations (Mahanadi, Godavari, Krishna and Kaveri) were having low genetic differentiation (Fst ranging from 0.00281 to 0.01362 , though statistically significant) indicating common ancestry in the prehistoric period and possible gene flow among these populations. This also holds good for Krishna-Kaveri and Narmada-Mahi suggesting possible connectivity and gene flow among them. Similar findings were reported in wild common carp (Li et al., 2007) and grass carp populations (Liu et al., 2009) in China using microsatellites. While studying mrigal from rivers belonging to Indus, Ganges and Brahmaputra basins using allozymes and microsatellites, Chauhan et al. (2007) reported low genetic differentiation. Also, studies using mitochondrial DNA of mrigal showed concordant results (Das et al., 2014, 
Table 3. No. of individuals ( $n$ ), no. of alleles (A), alleles per locus (Ap), expected heterozygosity (He), observed heterozygosity $(\mathrm{Ho})$, Fis value $(\mathrm{f})$ and $\mathrm{p}$ value for testing Hardy-Weinberg equilibrium in six populations of C.mrigala.

\begin{tabular}{|c|c|c|c|c|c|c|c|}
\hline Locus Name & Parameters & Mahanadi & Godavari & Krishna & Kaveri & Narmada & Mahi \\
\hline \multirow[t]{7}{*}{ Lr-206 } & $\mathrm{n}$ & 48 & 48 & 48 & 48 & 48 & 48 \\
\hline & $A$ & 6 & 12 & 12 & 6 & 9 & 8 \\
\hline & $A_{p}$ & 6 & 12 & 12 & 6 & 9 & 8 \\
\hline & $\mathrm{H}_{\mathrm{e}}$ & 0.787 & 0.794 & 0.799 & 0.732 & 0.773 & 0.817 \\
\hline & $\mathrm{H}_{\mathrm{o}}$ & 1.000 & 1.000 & 0.976 & 0.958 & 1.000 & 0.928 \\
\hline & $f$ & -0.274 & -0.262 & -0.224 & -0.312 & -0.297 & -0.138 \\
\hline & $\mathrm{P}$ & 0.098750 & 0.497188 & 0.156562 & 0.014687 & 0.419687 & 0.390000 \\
\hline \multirow[t]{7}{*}{ Lr298 } & $\mathrm{n}$ & 48 & 48 & 48 & 48 & 48 & 48 \\
\hline & $A$ & 8 & 7 & 11 & 11 & 12 & 12 \\
\hline & $A_{p}$ & 8 & 7 & 11 & 11 & 12 & 12 \\
\hline & $\mathrm{H}_{\mathrm{e}}$ & 0.808 & 0.748 & 0.876 & 0.849 & 0.884 & 0.819 \\
\hline & $\mathrm{H}_{\mathrm{o}}$ & 1.000 & 1.000 & 0.906 & 0.976 & 1.000 & 1.000 \\
\hline & $f$ & -0.241 & -0.340 & -0.034 & -0.151 & -0.133 & -0.223 \\
\hline & $\mathrm{P}$ & 0.308125 & 0.226250 & 0.267813 & 0.132812 & 0.397813 & 0.621250 \\
\hline \multirow[t]{7}{*}{ Lr36 } & $n$ & 48 & 48 & 48 & 48 & 48 & 48 \\
\hline & $A$ & 7 & 4 & 4 & 4 & 4 & 4 \\
\hline & $A_{p}$ & 7 & 4 & 4 & 4 & 4 & 4 \\
\hline & $\mathrm{H}_{\mathrm{e}}$ & 0.633 & 0.637 & 0.643 & 0.603 & 0.586 & 0.680 \\
\hline & $\mathrm{H}_{\mathrm{o}}$ & 1.00 & 1.00 & 0.818 & 0.833 & 0.918 & 1.00 \\
\hline & $f$ & -0.589 & -0.578 & -0.276 & -0.385 & -0.580 & -0.476 \\
\hline & $P$ & 0.056875 & 0.000000 & 0.030625 & 0.000313 & 0.013750 & 0.000000 \\
\hline \multirow[t]{7}{*}{ Lr162 } & $\mathrm{n}$ & 48 & 48 & 48 & 48 & 48 & 48 \\
\hline & $A$ & 5 & 8 & 5 & 5 & 9 & 8 \\
\hline & $A_{p}$ & 5 & 8 & 5 & 5 & 9 & 8 \\
\hline & $\mathrm{H}_{\mathrm{e}}$ & 0.728 & 0.825 & 0.607 & 0.648 & 0.801 & 0.764 \\
\hline & $\mathrm{H}_{\mathrm{o}}$ & 1.00 & 1.00 & 0.673 & 0.791 & 0.944 & 0.854 \\
\hline & $f$ & -0.378 & -0.214 & -0.109 & -0.223 & -0.181 & -0.118 \\
\hline & $P$ & 0.018750 & 0.107188 & 0.689375 & 0.308437 & 0.232500 & 0.219688 \\
\hline \multirow[t]{7}{*}{ Lr231a } & $n$ & 48 & 48 & 48 & 48 & 48 & 48 \\
\hline & $A$ & 8 & 9 & 10 & 10 & 10 & 19 \\
\hline & $A_{p}$ & 8 & 9 & 10 & 10 & 10 & 19 \\
\hline & $\mathrm{H}_{\mathrm{e}}$ & 0.770 & 0.837 & 0.797 & 0.782 & 0.820 & 0.860 \\
\hline & $\mathrm{H}_{\mathrm{o}}$ & 1.00 & 1.00 & 0.974 & 1.00 & 1.00 & 0.937 \\
\hline & $f$ & -0.302 & -0.197 & -0.225 & -0.281 & -0.223 & -0.091 \\
\hline & $P$ & 0.001250 & 0.000625 & 0.013437 & 0.253125 & 0.006875 & 0.001250 \\
\hline \multirow[t]{7}{*}{ Lr485 } & $\mathrm{n}$ & 48 & 48 & 48 & 48 & 48 & 48 \\
\hline & $A$ & 6 & 7 & 11 & 10 & 5 & 10 \\
\hline & $A_{p}$ & 6 & 7 & 11 & 10 & 5 & 10 \\
\hline & $\mathrm{H}_{\mathrm{e}}$ & 0.750 & 0.733 & 0.767 & 0.811 & 0.721 & 0.728 \\
\hline & $\mathrm{H}_{\mathrm{o}}$ & 1.00 & 1.00 & 0.872 & 1.00 & 1.00 & 1.00 \\
\hline & $f$ & -0.337 & -0.368 & -0.138 & -0.235 & -0.394 & -0.377 \\
\hline & $\mathrm{P}$ & 0.081562 & 0.000000 & 0.820000 & 0.264062 & 0.001250 & 0.367812 \\
\hline \multirow[t]{7}{*}{ Lr237 } & $\mathrm{n}$ & 48 & 48 & 48 & 48 & 48 & 48 \\
\hline & $A$ & 5 & 6 & 10 & 10 & 11 & 11 \\
\hline & $A_{p}$ & 5 & 6 & 10 & 10 & 11 & 11 \\
\hline & $\mathrm{H}_{\mathrm{e}}$ & 0.791 & 0.817 & 0.827 & 0.797 & 0.796 & 0.832 \\
\hline & $\mathrm{H}_{\mathrm{o}}$ & 1.00 & 1.00 & 1.00 & 1.00 & 1.00 & 1.00 \\
\hline & $f$ & -0.267 & -0.225 & -0.211 & -0.257 & -0.259 & -0.204 \\
\hline & $P$ & 0.047500 & 0.001563 & 0.563125 & 0.364063 & 0.662500 & 0.079062 \\
\hline \multirow[t]{7}{*}{ Lr545 } & $\mathrm{n}$ & 48 & 48 & 48 & 48 & 48 & 48 \\
\hline & $A$ & 6 & 8 & 5 & 5 & 8 & 8 \\
\hline & $A_{p}$ & 6 & 8 & 5 & 5 & 8 & 8 \\
\hline & $\mathrm{H}_{\mathrm{e}}$ & 0.655 & 0.660 & 0.666 & 0.692 & 0.657 & 0.670 \\
\hline & $\mathrm{H}_{\mathrm{o}}$ & 1.00 & 1.00 & 0.840 & 1.00 & 0.944 & 0.979 \\
\hline & $f$ & -0.535 & -0.522 & -0.264 & -0.449 & -0.445 & -0.467 \\
\hline & $P$ & 0.000000 & 0.044062 & 0.279062 & 0.001250 & 0.192188 & 0.153750 \\
\hline \multirow[t]{7}{*}{ Lr251a } & $\mathrm{n}$ & 48 & 48 & 48 & 48 & 48 & 48 \\
\hline & $A$ & 7 & 6 & 10 & 6 & 8 & 9 \\
\hline & $A_{p}$ & 7 & 6 & 10 & 6 & 8 & 9 \\
\hline & $\mathrm{H}_{\mathrm{e}}$ & 0.734 & 0.714 & 0.690 & 0.659 & 0.747 & 0.739 \\
\hline & $\mathrm{H}_{\mathrm{o}}$ & 0.955 & 1.00 & 0.844 & 0.812 & 0.953 & 0.978 \\
\hline & $f$ & -0.304 & -0.404 & -0.225 & -0.235 & -0.279 & -0.327 \\
\hline & $P$ & 0.025625 & 0.002188 & 0.026875 & 0.447500 & 0.214688 & 0.246250 \\
\hline \multirow[t]{2}{*}{ Lr432 } & $\mathrm{n}$ & 48 & 48 & 48 & 48 & 48 & 48 \\
\hline & $A$ & 10 & 6 & 15 & 12 & 11 & 12 \\
\hline
\end{tabular}




\begin{tabular}{|c|c|c|c|c|c|c|c|}
\hline \multicolumn{8}{|c|}{ Table 3 continued } \\
\hline Locus Name & Parameters & Mahanadi & Godavari & Krishna & Kaveri & Narmada & Mahi \\
\hline & $A_{p}$ & 10 & 6 & 15 & 12 & 11 & 12 \\
\hline & $\mathrm{H}_{\mathrm{e}}$ & 0.717 & 0.770 & 0.845 & 0.852 & 0.862 & 0.827 \\
\hline & $\mathrm{H}_{\mathrm{o}}$ & 1.00 & 1.00 & 0.971 & 1.00 & 1.00 & 1.00 \\
\hline & $f$ & -0.400 & -0.303 & -0.151 & -0.175 & -0.161 & -0.211 \\
\hline & $P$ & 0.085000 & 0.015938 & 0.104063 & 0.246562 & 0.710625 & 0.503750 \\
\hline \multirow[t]{7}{*}{ Lr547 } & $n$ & 48 & 48 & 48 & 48 & 48 & 48 \\
\hline & $A$ & 8 & 9 & 5 & 9 & 8 & 11 \\
\hline & $A_{p}$ & 8 & 9 & 5 & 9 & 8 & 11 \\
\hline & $\mathrm{H}_{\mathrm{e}}$ & 0.688 & 0.677 & 0.641 & 0.667 & 0.725 & 0.747 \\
\hline & $\mathrm{H}_{\mathrm{o}}$ & 0.825 & 0.851 & 0.864 & 0.895 & 0.941 & 0.869 \\
\hline & f & -0.201 & -0.260 & -0.355 & -0.345 & -0.303 & -0.165 \\
\hline & $P$ & 0.005313 & 0.450313 & 0.112500 & 0.271250 & 0.506563 & 0.100625 \\
\hline \multirow[t]{7}{*}{ Lr158 } & $n$ & 48 & 48 & 48 & 48 & 48 & 48 \\
\hline & $A$ & 27 & 22 & 18 & 22 & 22 & 22 \\
\hline & $A_{p}$ & 27 & 22 & 18 & 22 & 22 & 22 \\
\hline & $\mathrm{H}_{\mathrm{e}}$ & 0.959 & 0.937 & 0.936 & 0.931 & 0.926 & 0.922 \\
\hline & $\mathrm{H}_{\mathrm{o}}$ & 1.00 & 1.00 & 1.00 & 1.00 & 1.00 & 1.00 \\
\hline & $f$ & -0.042 & -0.067 & -0.069 & -0.074 & -0.080 & -0.085 \\
\hline & $P$ & 0.035625 & 0.156250 & 0.991250 & 0.586875 & 0.724063 & 0.556562 \\
\hline \multirow[t]{7}{*}{ Lr51a } & $\mathrm{n}$ & 48 & 48 & 48 & 48 & 48 & 48 \\
\hline & $A$ & 9 & 8 & 17 & 11 & 10 & 11 \\
\hline & $A_{p}$ & 9 & 8 & 17 & 11 & 10 & 11 \\
\hline & $\mathrm{H}_{\mathrm{e}}$ & 0.789 & 0.836 & 0.768 & 0.728 & 0.837 & 0.829 \\
\hline & $\mathrm{H}_{\mathrm{o}}$ & 0.928 & 1.000 & 0.863 & 0.953 & 0.931 & 1.000 \\
\hline & f & -0.178 & -0.198 & -0.124 & -0.314 & -0.114 & -0.207 \\
\hline & $P$ & 0.112187 & 0.034063 & 0.053125 & 0.670000 & 0.545625 & 0.338438 \\
\hline \multirow[t]{7}{*}{ Lro32 } & $n$ & 48 & 48 & 48 & 48 & 48 & 48 \\
\hline & $A$ & 5 & 5 & 5 & 4 & 6 & 5 \\
\hline & $A_{p}$ & 5 & 5 & 5 & 4 & 6 & 5 \\
\hline & $\mathrm{He}_{\mathrm{e}}$ & 0.717 & 0.639 & 0.629 & 0.625 & 0.740 & 0.716 \\
\hline & $\mathrm{H}_{\mathrm{o}}$ & 0.888 & 0.729 & 0.871 & 0.790 & 0.733 & 0.785 \\
\hline & f & -0.242 & -0.141 & -0.391 & -0.268 & 0.010 & -0.098 \\
\hline & $P$ & 0.010625 & 0.000000 & 0.100937 & 0.044375 & 0.104375 & 0.303750 \\
\hline \multirow[t]{7}{*}{ Lr198 } & $n$ & 48 & 48 & 48 & 48 & 48 & 48 \\
\hline & $A$ & 16 & 16 & 15 & 16 & 15 & 15 \\
\hline & $A_{p}$ & 16 & 16 & 15 & 16 & 15 & 15 \\
\hline & $\mathrm{H}_{\mathrm{e}}$ & 0.917 & 0.899 & 0.894 & 0.871 & 0.881 & 0.901 \\
\hline & $\mathrm{H}_{\mathrm{o}}$ & 1 & 1 & 1 & 1 & 1 & 1 \\
\hline & f & -0.090 & -0.113 & -0.119 & -0.149 & -0.137 & -0.110 \\
\hline & $P$ & 0.701562 & 0.106563 & 0.298750 & 0.739375 & 0.798125 & 0.715938 \\
\hline \multirow[t]{7}{*}{ Lr-63 } & $n$ & 48 & 48 & 48 & 48 & 48 & 48 \\
\hline & $A$ & 17 & 18 & 12 & 15 & 16 & 15 \\
\hline & $A_{p}$ & 17 & 18 & 12 & 15 & 16 & 15 \\
\hline & $\mathrm{H}_{\mathrm{e}}$ & 0.922 & 0.908 & 0.855 & 0.868 & 0.873 & 0.904 \\
\hline & $\mathrm{H}_{\mathrm{o}}$ & 1 & 1 & 0.955 & 0.979 & 0.944 & 1 \\
\hline & f & -0.084 & -0.101 & -0.118 & -0.129 & -0.082 & -0.106 \\
\hline & $P$ & 0.643125 & 0.049688 & 0.426250 & 0.658438 & 0.327500 & 0.279062 \\
\hline \multirow[t]{7}{*}{ Lro-41 } & $n$ & 48 & 48 & 48 & 48 & 48 & 48 \\
\hline & $A$ & 9 & 11 & 7 & 7 & 11 & 12 \\
\hline & $A_{p}$ & 9 & 11 & 7 & 7 & 11 & 12 \\
\hline & $\mathrm{H}_{\mathrm{e}}$ & 0.726 & 0.779 & 0.607 & 0.705 & 0.822 & 0.775 \\
\hline & $\mathrm{H}_{\mathrm{o}}$ & 1 & 1 & 0.595 & 0.75 & 1 & 0.937 \\
\hline & f & -0.382 & -0.286 & 0.02 & -0.063 & -0.219 & -0.211 \\
\hline & $P$ & 0.051250 & 0.005938 & 0.051250 & 0.008438 & 0.759062 & 0.847500 \\
\hline
\end{tabular}

Table 4. AMOVA of microsatellite markers of six Peninsular riverine populations of Cirrhinus mrigala.

\begin{tabular}{lcccc}
\hline Source of variation & d.f. & Sum of squares & Variance components & Percentage of variation \\
\hline Among populations & 5 & 58.426 & $0.10532 \mathrm{Va}$ & 5.46 \\
Within populations & 556 & 1013.528 & $1.82289 \mathrm{Vb}$ & 94.54 \\
Total & 561 & 1071.954 & 1.92821 & 100 \\
Fixation Index FST : 0.05462 & & & & \\
\hline
\end{tabular}


Table 5. Fst Values of mrigal across six peninsular rivers

\begin{tabular}{llllll} 
& Mahanadi & Godavari & Krishna & Kaveri & Narmada \\
\hline Mahanadi & 0.00000 & & & & \\
Godavari & 0.00330 & 0.00000 & & & \\
Krishna & 0.01780 & 0.00112 & 0.00000 & & \\
Kaveri & 0.02146 & 0.01636 & 0.00565 & 0.00000 & 0.00000 \\
Narmada & 0.08027 & 0.08668 & 0.10662 & 0.09898 & -0.00644 \\
Mahi & 0.08529 & 0.08973 & 0.09740 & 0.10082 & 0.00000 \\
\hline
\end{tabular}

2018, Behera et al., 2015). In the present study, only Narmada and Mahi populations were highly differentiated from all others. This may be acceptable because these two peninsular rivers are geographically in west coast of India flowing to Arabian Sea and the other four rivers are in the east coast flowing to Bay of Bengal. Different environment induces population genetic structure because of the different habitats isolated regionally. Further, in freshwater fishes fragmented populations are expected to exhibit high genetic differentiation (Ward et al., 1994).

In spite of the popularity of microsatellites in the study of population genetics, their development requires substantial time, financial as well as technical resources. Cross-species amplification in the present study allowed using heterologous primers to describe genetic diversity and population structure of a potential carp species mostly cultivated in the country. The result established a single genetic stock of Cirrhinus mrigala in Peninsular regions of India inferred from microsatellite markers because during the Eocene period the genus Cirrhinus is believed to have entered India following migration of Indo-Malayan fishes via the Indo-Brahma River, flowing westward from Assam in the north-east to the present-day Arabian Sea (Daniels, 2001) specifying a common origin of this species in Indian rivers. Also, low genetic differentiation is most probably a result of gene flow due to human introduction of this species to rivers, unethical aquaculture practices, natural calamities, etc. in the absence of connectivity among the rivers. The results of this study will definitely update the breeders and conservationists while planning for genetic improvement by developing base population for longterm genetic gain and conservation of this species.

\section{Ethical Statement}

Not applicable.

\section{Funding Information}

The financial support for this work was provided by the Indian Council of Agricultural Research, New Delhi under Outreach activity on "Fish genetic stocks".

\section{Author Contribution}

S.P.D.: Conceptualization, Methodology, Data curation, Sample collection Writing - original draft.
S.K.S.: Helped in Sample collection and Data analysis. L.S.: Sample collection. J.K.J.: Conceptualized. P.D.: Conceptualized, Supervision, Project administrator, review and editing.

\section{Conflict of Interest}

The authors declare that they have no known competing financial interests or personal relationships that could have appeared to influence the work reported in this paper.

\section{Acknowledgements}

The financial support for this work was provided by the Indian Council of Agricultural Research, New Delhi under Outreach activity on "Fish genetic stocks". The authors are thankful to the Director, ICAR-Central Institute of Freshwater Aquaculture for providing facilities to work.

\section{References}

Allendorf, F.W., Utter, F.M., 1979. Population genetics. In: W.S. Hoar, D.J. Randall, and J.R. Brett (Eds), Fish Physiology. Academic Press, New York. Strauss \& Bookstein, 1982, Volume. 8, pp. 407-454.

Aranishi, F., Okimoto. T., 2005. Sequence polymorphism in a novel noncoding region of Pacific oyster mitochondrial DNA. J. Appl. Genet. 46: 201-206.

An, H.S., Lee, J.W., Hong, S.W., 2013. Population genetic structure of the Korean Pacific abalone Haliotis diversicolor supertexta inferred from microsatellite marker analysis. Biochem. Syst. Ecol. 48: 76-94.

Barat, A., Chandra, S., Singh, B.K., Matura, R., Mahanta, P.C., 2011. Successful cross-amplification of few microsatellite loci isolated from Tor tambroides for indian snow trout, Schizothorax richardsonii (Gray, 1832) (Family: Cyprinidae). Gl. J. Mol. Sci. 6: 22-25.

Behera, B.K., Kunal, S.P., Paria, P., Das, P., Meena, D.K., Pakrashi, S., Sahoo, A.K., Panda, D., Jena, J., Sharma, A.P., 2015. Genetic differentiation in Indian Major Carp, Cirrhinus mrigala (Hamilton, 1822) from Indian Rivers, as revealed by direct sequencing analysis of mitochondrial Cytochrome b region. Mitochondrial. DNA. A., 26: 334336.

Chauhan, T., Lal, K.K., Mohindra, V., Singh, R.K., Punia, P., Gopalakrishnan, A., Sharma, P.C., Lakra, W.S., 2007. Evaluating genetic differentiation in wild populations of the Indian major carp, Cirrhinus mrigala (HamiltonBuchanan, 1882): evidence from allozyme and microsatellite markers. Aquacult. 269: 135-149. 
Daniels, R.J.R., 2001. Endemic fishes of the Western Ghats and the Satpura hypothesis. Curr. Sci. 81:240-244

Das, P., Barat, A., Meher, P.K., Ray, P.P., Majumdar, D., 2005. Isolation and characterization of polymorphic microsatellites in Labeo rohita and their cross-species amplification in related species. Mol. Ecol. Notes. 5: 231233.

Das, S.P., Bej, D., Swain, S., Mishra, C.K., Sahoo, L., Jena, J., Jayasankar, P., Das, P., 2014. Population divergence and structure of Cirrhinus mrigala from peninsular rivers of India, revealed by mitochondrial cytochrome $b$ gene and truss morphometric analysis. Mitochondrial. DNA. A. $25: 157-164$

Das, S.P., Swain, S., Jena, J., Das, P., 2018. Genetic diversity and population structure of Cirrhinus mrigala revealed by mitochondrial ATPase 6 gene. Mitochondrial. DNA. A. 29: $495-500$

Esa, Y., Siraj, S.S., Daud, S.K., A Rahim, K.A., Japning, J.R.R., Soon, G.T., 2008. Mitochondrial DNA diversity of Tor tambroides Valenciennes (Cyprinidae) from five natural populations in Malaysia. Zool. Stud. 47:360-367.

FAO (2012). The state of the world fisheries and aquaculture. Food and Agriculture Organization of the United Nations, Rome

FAO (2020). National Aquaculture Sector Overview, India. National Aquaculture Sector Overview Fact Sheets. Text by Ayyappan, S. In: FAO Fisheries Division, Rome.

Falush, D., Stephens, M., Pritchard, J.K., 2003. Inference of population structure using multilocus genotype data: linked loci and correlated allele frequencies. Genetics. 164: 1567-1587.

Falush, D., Stephens, M., Pritchard, J.K., 2007. Inference of population structure using multilocus genotype data: dominant markers and null alleles. Mol. Ecol. Notes. 7: 574-578.

Frankham, R., 1996. Relationship of genetic variation to population size in wildlife. Conserv. Biol. 10: 1500-1508.

Kim, W.J., Shin, E.H., Kong, H.J., Nam, B.H., Kim, Y.O., Jung, H., An, C.M., 2013. Development of polymorphic microsatellite markers Suitable for genetic linkage mapping of Olive Flounder Paralichthys olivaceus. Fish. Aquat. Sci. 16: 303-309.

Lewis, P.O., Zaykin, D., 2000. Genetic data analysis: computer programme for analysis of allelic data, version1.0. Available at http://hydrodictyon.eeb.uconn. edu/people/plewish/software.php

Li, D., Kang, D., Yin, Q., Sun, X., Liqun, L., 2007. Microsatellite DNA marker analysis of genetic diversity in wild common carp (Cyprinus carpio L.) populations. J. Gen. Genom. 34: 984-993.

Liu, F., Xia, J.H., Bai, Z.Y., Fu, J.J., Li, J.L., Yue, G.H. 2009., High genetic diversity and substantial population differentiation in grass carp (Ctenopharyngodon idella) revealed by microsatellite analysis. Aquacult. 297: 51-56.

Mohindra, V., Mishra, A., Palanichamy, M., Ponniah, A.G., 2001. Cross-species amplification of Catla catla microsatellite locus in Labeo rohita. Ind. J. Fish. 48: 103108

Nevo, E., 1978. Genetic variation in natural populations: patterns and theory. Theo. Pop. Biol. 13: 121-177.

Nevo, E., Beiles, A., Ben-Shlomo, R., 1984. The evolutionary significance of genetic diversity: ecological, demographic and life history correlates. Springer Berlin Heidelberg, pp. 13-213.

Nei, M., 1972. Genetic distance between populations. Am. natura. 283-292.

Olafsson, K., Hjorleifsdottir, S., Pampoulie, C., Hreggvidsson, G.O., Gudjonsson, S., 2010. Novel set of multiplex assays (SalPrint15) for efficient analysis of 15 microsatellite loci of contemporary samples of the Atlantic salmon (Salmo salar). Mol. Ecol. 10: 533-537.

Patel, A., Das, P., Swain, S. K., Meher, P. K., Jayasankar, P., Sarangi, N., 2009. Development of 21 new microsatellite markers in Labeo rohita (rohu). Anim. Genet. 40: 251254.

Payne, A.I., Sinha, R., Singh, H.R., Huq, S., 2004. A review of Ganges basin: its fish and fisheries, in: R. Welcomme, T. Petr (Eds.), Proceedings of the second International Symposium on the Management of Large Rivers for Fisheries, Sustaining Livelihoods and Biodiversity in the New Millennium. FAO Regional Office for Asia and the Pacific, Bangkok, Thailand. RAP Publication 2004/16, vol.

Porta, J., Porta, J.M., Martinez-Rotriguez, G., Alvarez, M.D.C., 2006. Development of a microsatellite multiplex PCR for Senegalese sole (Solea senegalensis) and its application to broodstock management. Aquacult. 56: 159 - 166.

Primmer, C.R., Møller, A.P., Ellegren, H., 1996. A wide-range survey of cross-species microsatellite amplification in birds. Mol. Ecol. 5: 365-378.

Pritchard, J.K., Stephens, M., Donnelly, P., 2000. Inference of population structure using multilocus genotype data. Genetics. 155: 945-959.

Sahu, B.P., Patel, A., Sahoo, L., Das, P., Meher, P.K., Jayasankar, P., 2012. Rapid and cost effective development of SSR markers using next generation sequencing in Indian major carp, Labeo rohita (Hamilton, 1822). Ind. J. Fish. 59: 21-24.

Sambrook, J., Russell, D.W., 2001. Molecular cloning: a laboratory manual, 2 ed. CSHL Press

Talwar, P.K., Jhingran, A.G., 1991. Inland Fishes of India and Adjacent Countries. A.A. Balkema, Rotterdam, 541pp.

Tautz, D., 1989. Hypervariability of simple sequences as a general source for polymorphic DNA markers. Nuc. Acid. Res. 17: 6463-6471.

Van Oosterhout, C., Hutchinson, W.F., Wills, D.P.M., Shipley, P., 2004. Micro Checker: software for identifying and correcting genotyping errors in microsatellite data. Mol. Ecol. Notes. 4: 535-538.

Ward, R.D., Grewe, P.M., 1994. Appraisal of molecular genetic techniques in fisheries. Rev. Fish. Biol. Fish. 4: 300-325. 